\title{
Crítica al marxismo estándar, al socialismo real y al anarquismo bakuninista desde la perspectiva liberacionista*
}

Fecha de entrega: 30 de octubre de 2018

Fecha de evaluación: 13 de diciembre de 2018

Fecha de aprobación: 20 de enero de 2019

\section{J. Alfredo Ochoa Gómez **}

\section{Resumen}

En su libro Política de la liberación. Volumen II: arquitectónica, Enrique Dussel emprende el análisis de la filosofía política burguesa para deconstruir el orden vigente que instauró la modernidad colonizadora, e incluye alternativas como el marxismo estándar, el socialismo real y el anarquismo de izquierda.

En este sentido, el presente texto rastrea la disquisición del maestro de la liberación latinoamericana por todo el eje de la crítica enunciada

* Este texto parte de otro documento de reflexión filosófica titulado "Deconstrucción de la izquierda e interpretación reductiva del anarquismo en la arquitectónica dusseliana". Para efecto de la participación en el XVII Congreso Internacional de Filosofía Latinoamericana se han establecido cambios en su estructura y contenido que no modifican la apuesta conceptual original. El documento matriz hace parte del repositorio de los trabajos de grado de la Maestría en Filosofía Latinoamericana (Ochoa, 2015). Citar como Ochoa Gómez, J. A. (2019). Crítica al marxismo estándar, al socialismo real y al anarquismo bakuninista desde la perspectiva liberacionista. Cuadernos de Filosofía Latinoamericana, 40(120), 121-137. DOI: 10.15332/25005375/5381

* Licenciado en Ciencias Sociales de la Universidad Distrital Francisco José de Caldas. Magister en Filosofía Latinoamericana de la Universidad Santo Tomás. Profesor investigador del Departamento de Filosofía de Uniminuto. Miembro del grupo de investigación Pensamiento, Filosofia y Sociedad de la misma institución. Correos electrónicos: johnni.ochoa@uniminuto.edu y jocho8a8@gmail.com 
y a través de las principales categorías que desarrolla en su arquitectónica, a saber: 1) en los niveles de la acción estratégica; 2) en el nivel político-institucional; 3 ) en el nivel de los principios implícitos fundamentales.

Por otro lado, se sugiere un equívoco conceptual en el que Dussel incurriría acerca del anarquismo de izquierda - craso error tratándose de la teoría política que junto al marxismo ha acometido la lucha revolucionaria contra el orden burgués-. Este señalamiento no debe confundirse con una empresa antitética a la dusseliana pues se reconoce como expresión disidente pero comprometida con el proceso liberacionista.

Palabras clave: política de la liberación, ontología, izquierda, marxismo estándar, socialismo real.

\section{Critique of standard Marxism, real socialism and Bakuninist anarchism from a liberationist perspective}

\section{Abstract}

In his book Politics of liberation. Volume II: Architecture, Enrique Dussel undertakes the analysis of bourgeois political philosophy to deconstruct the current order that established the colonizing modernity, and includes alternatives such as standard Marxism, real socialism and left anarchism.

In this sense, the present article traces the disquisition of the Latin American liberation teacher along the axis of the critique enunciated and through the main categories that he develops in his architecture, namely: 1) at the levels of strategic action; 2) at the political-institutional level; 3 ) at the level of the fundamental implicit principles.

On the other hand, a conceptual equivocation is suggested in which Dussel would incur about left anarchism - a serious mistake in the case of the political theory that, together with Marxism, has 
undertaken the revolutionary struggle against the bourgeois order-. This finger-pointing should not be confused with an enterprise antithetical to the Dusselian one because it is recognized as a dissident expression but committed to the liberationist process.

Keywords: Politics of liberation, ontology, left, standard Marxism, real socialism, left anarchism.

\section{A modo de introducción}

Este trabajo tiene como marco conceptual la Arquitectónica (2009), segundo volumen de la colección Política de la Liberación que el filósofo argentino-mexicano Enrique Dussel inició en 2007 con Historia mundial y crítica $^{1}$ y que, se espera, terminará con un volumen intitulado "Crítica". Sobre estas obras, la primera y la última, basta decir que responden respectivamente a la demanda historiográfica de "contar" el devenir de la humanidad desde la perspectiva de los vencidos, y a la necesidad de transformar el orden político vigente de la modernidad colonizadora. Demanda y necesidad entre las cuales se ubica la obra que enmarca conceptualmente la reflexión expuesta en este escrito, que en palabras del mentado filósofo constituye un "rompecabezas" (Dussel, 2009, p. 37) de categorías cuya finalidad es el desarrollo de una ontología de la política.

Ahora bien, aunque la empresa intelectual de nuestro filósofo emprende principalmente el análisis del sistema de categorías fenoménicas de la filosofía política burguesa para deconstruir el orden que instauró la Modernidad colonizadora, dicha deconstrucción no aborda exclusivamente al pensamiento liberal ${ }^{2}$. Dirige su análisis también a las alternativas que no superaron los diques de tal modernidad, alternativas entre

1 Para establecer una relación preliminar con esta obra inaugural de la política de la liberación se sugiere leer el excelente artículo "Historiografía, eurocentrismo y universalidad en Enrique Dussel" (Pachón, 2012).

2 Por pensamiento liberal ha de entenderse, en sentido amplio, el correspondiente a la filosofía politica burguesa. Esta aclaración cobra sentido en la medida en que en la Arquitectónica constantemente el autor matiza diferentes perspectivas teóricas que tienen seno en esta filosofía con denominaciones como conservadurismo, liberalismo, neoconservadurismo, neoliberalismo. Denominaciones que a su vez adjetiva con otras como tradicional, parlamentarista, reformista, etc. Pensamiento liberalse refiere entonces al que por antonomasia identifica a la filosofia burguesa en cualquiera de sus variantes. 
las que encontramos, en palabras de Dussel, al marxismo estándar, al socialismo real $\mathrm{y}$ al anarquismo de izquierda.

En este sentido, el título del presente ensayo implica rastrear la disquisición de Dussel respecto al eje de la deconstrucción enunciada en busca de las críticas que formula al marxismo estándar, el socialismo real y el anarquismo de izquierda a través de las principales categorías de la obra de marras (acción estratégica, institución, principios implícitos fundamentales). Ahora bien, antes de abordar la deconstrucción de la izquierda en los niveles arquitectónicos, conviene delinear sucintamente cada una de las partes del referido tríptico antiburgués con el ánimo de comprender su sentido en el contexto de la reflexión que aquí se ofrece. Veamos.

Hablar de marxismo estándar y socialismo real implica suponer los vínculos que identifican a estas perspectivas ideológicas como una corriente que mantuvo la posición hegemónica dentro de la izquierda hasta el colapso de la URss en 1989. Ahora, la diferenciación obedece a que estas expresiones del llamado por Dussel dogmatismo de izquierda recibieron directamente la impronta de la filosofía althusseriana, en el primer caso, y de la experiencia soviética, en el segundo. En cuanto al anarquismo, en algunos apartados de este ensayo con tal calificativo se identifica tácitamente a un movimiento variopinto de izquierda, y en otras líneas se explicita con la denominación anarquismo de izquierda, siguiendo la terminología de la Arquitectónica para distinguirlo de un movimiento diferente que entroniza el libre mercado y es señalado por Dussel como anarquismo de derecha. Ahora, al respecto es menester señalar, en razón del objeto de nuestra reflexión, que el primer tipo de anarquismo, el de izquierda, es para Dussel básicamente el de Mijaíl Bakunin³

En este orden de ideas, las siguientes líneas abordarán la deconstrucción de la izquierda en los siguientes momentos: a) en el nivel de la acción estratégica, b) en el nivel político-institucional y c) en el nivel de los principios implícitos fundamentales.

3 Sin que la empresa filosófica de Dussel deje de ser loable, una de las críticas que cabe hacerle a quien promueve en clave marxista-liberacionista la transontologización para superar el orden liberal es soslayar la obra de teóricos de primer orden en la izquierda revolucionaria, como Enrico Malatesta y Piotr Kropotkin. Al respecto, basta mirar con asombro que en la ingente bibliografia que se relaciona en la Arquitectónica la mención a este tipo de autores preeminentes es nula. Asombroso en tanto que la propuesta de Dussel guarda grandes simetrias conceptuales con la del príncipe ruso -ver al respecto Génesis y desarrollo de la filosofía social de Kropotkin (Cappelletti, 1978)-. 


\section{Deconstrucción de la izquierda por niveles arquitectónicos}

\section{En el nivel de la acción estratégica}

En este nivel Dussel establece el análisis de los siguientes, a su juicio, equívocos conceptuales, políticos e históricos de la izquierda en materia de acción políticoestratégica, a saber: el carácter metafísico que reviste al economicismo y a la confianza en el proletario como sujeto revolucionario, la "estadolatría” de la lucha política del marxismo estándar, la disolución del Estado que enarbola el anarquismo y la teorización desmesurada alrededor de los términos infraestructura y superestructura, que para nuestro filósofo son apenas metáforas "sin intención teórica” (Dussel, 2009, p. 168) en Marx. En este orden de ideas, las siguientes líneas desarrollan sintéticamente el análisis expuesto por Dussel.

Para empezar, sobre el economicismo señala que el marxismo estándar transfirió el concepto ley, propio de las ciencias naturales, a la comprensión del devenir histórico de la humanidad para establecer como ineluctable la superación del capitalismo por el socialismo en razón de supuestas leyes económicas. Trasferencia frente a la cual plantea la siguiente pregunta: “¿Para qué entonces la acción política si el triunfo estaba ya garantizado, como que el sol sale cada mañana?" (Dussel, 2009, p. 32).

En cuanto a la identificación del Estado como objeto consustancial de la política, señala el carácter falaz y reduccionista que determina a la acción estratégica en el marxismo estándar. Contra esa falacia se alzaron teóricos como Gramsci - marxista de otro cuño- y Foucault, quienes identificaron la política con la dinámica de poder de microinstituciones que desbordan al Estado y están ancladas a la sociedad y a sus agentes en general.

Otro alzamiento contra la falacia enunciada proviene del anarquismo, postura que acertadamente arremete contra la "fórmula" revolucionaria de la "toma del poder del Estado" cayendo, sin embargo, en otro reduccionismo pues soslaya la importancia del Estado al identificar exclusivamente la política con la aniquilación de aquel.

Frente a la consideración del proletariado como el sujeto histórico por antonomasia de la revolución, Dussel cuestiona a la izquierda porque esta concepción convierte a la 
clase obrera en una sustancia metafísica, y se olvida así que existen otros sujetos más allá del proletariado que también luchan por la liberación política.

La comprensión de lo político para la empresa de la liberación encuentra en Ernesto Laclau un teórico de primer orden por su crítica al dogmatismo de izquierda del marxismo estándar, particularmente por su cuestionamiento del anquilosamiento conceptual que representa el economicismo. Laclau incurre, sin embargo, en equívocos, al no diferenciar entre las falacias del marxismo estándar y la obra de Marx. Por ejemplo: dicho marxismo presenta al mercado como un orden autorregulado que determina la competencia entre los actores económicos, cuando desde la perspectiva de Marx aparece como un automatismo externo a la sociedad como consecuencia del individualismo en el que caen los actores económicos. Dicho de otro modo: el mercado no está determinado por leyes externas a la voluntad y las posibilidades de los actores económicos.

En este sentido, el economicismo constituye un disolvente teórico de lo político al plantear como lógico y necesario en la lucha revolucionaria el mero cambio del modo de producción capitalista. En cambio, desde una perspectiva ajena a dicho disolvente, la lucha revolucionaria implica concebir lo político como algo que desborda la prescripción de las formulas económicas y se ocupa del discernimiento de las contingencias que determinan a las sociedades para definir en consecuencia las estrategias que llevarían a su transformación.

Desde la perspectiva de Laclau el pensamiento de Gramsci posibilitó la superación de la tesis de la lucha de clases entre burguesía y proletariado, tesis del marxismo clásico, pese a que su obra sigue siendo rehén del principio por el cual se considera que esta última clase social es portadora de la "misión” ontológica de refundar el orden social. En este sentido, el marxista italiano asestó, pese a sí mismo, un golpe contra la dictadura del proletariado y en favor de la pluralidad histórica de los sujetos.

En este orden de ideas la lucha contra el liberalismo, contra la burguesía, implica entonces la hegemonía que logren los actores políticos a través de la estrategia del consenso intersubjetivo. Esta estrategia va más allá de la simple alianza entre quienes comparten presupuestos ideológicos afines y establecen acuerdos formales, puesto que implica el reconocimiento entre actores políticos que representan diferentes subjetividades. 
Ahora, desde la perspectiva gramsciana, la hegemonía representa la legitimación del gobierno de una clase social a partir del consenso alcanzado por la mayoría de los actores políticos involucrados. Dicha legitimación dista sustancialmente de la dominación de impronta weberiana ${ }^{4}$ o la uniformidad ideológica del marxismo estándar, y además va más allá del mero acuerdo racional-discursivo de corte habermasiano.

En lo que respecta a las categorías infraestructura y superestructura, tan caras al marxismo estándar, no reflejan el pensamiento dialéctico de Marx pues yuxtaponen conceptos como producción, consumo, distribución, capital y Estado en una relación de subordinación de lo político (lo superestructural) a lo económico (lo infraestructural). En este sentido, dichas categorías constituyen en la obra de Marx metáforas sin pretensión teórica.

En definitiva, la izquierda debe asimilar el proceso histórico que entre 1917 y 1989 determinó el curso del denominado socialismo real en la Unión Soviética, por el cual se constatan con creces los estragos sociales y políticos de un economicismo metafísico que tradujo como revolución socialista el retraso de un porcentaje considerable de la humanidad a causa del burocratismo igualitarista y el despotismo "político" de un Estado fisgón y pretendidamente proletario cuyo gran mérito fue abortar la política en función de una economía estatizada y la concentración del poder en un partido único. Dicho de otro modo: el economicismo metafísico desvirtuó el proyecto socialista deslegitimándolo al perder progresivamente la hegemonía que lograron los soviets cuando el siglo $\mathrm{xx}$ apenas despuntaba.

\section{En el nivel político institucional}

En el segundo nivel de la Arquitectónica Dussel hace el análisis de los equívocos de la izquierda en torno a las instituciones que determinan el orden político. De este modo, las consideraciones que expone versan sobre los siguientes temas: la codeterminación entre las esferas material (lo económico), formal (lo político) y de factibilidad institucional en función de la producción y el acrecentamiento de la vida (última instancia de un nuevo orden ontológico-político); los reduccionismos que se extienden en el denso entramado de las teorías que orbitan en torno a la razón discursivo-política,

4 "Por dominación debe entenderse la probabilidad de encontrar obediencia a un mandato de determinado contenido entre personas dadas" (Weber, 2012, p. 43). 
el marxismo estándar y los postulados anarquistas; las consecuencias del individualismo metafísico del liberalismo en la relación libertad-justicia y las funciones cumplidas por "microsistemas políticos diseminados en todo el cuerpo social y político" (Dussel, 2009, p. 249), como el ejército y la religión -elementos denostados por la izquierda tradicional-, el mercado y sobre todo el Estado. A continuación se detallan las consideraciones enunciadas.

No existe una última instancia que imponga un orden entre las esferas material (lo económico) y formal (lo político). De ser así no existiría forma de superar los reduccionismos del economicismo y el politicismo. Ahora bien, la relación entre ambas esferas implica la existencia de otra, la esfera de factibilidad institucional, que posibilita la realización empírica de proyectos de sociedad diferentes a la liberal y a la que impuso el socialismo real. Desde esta perspectiva las tres esferas son codeterminantes y necesarias en el diseño y construcción de sociedades alternativas a la del orden vigente. Se entiende, en consecuencia, que ninguna se basta a sí misma o es suficiente en sí, como lo evidencian las propuestas de Arendt, Rawls o Habermas, que ponen el acento en la esfera formal, o el marxismo estándar, cuyo énfasis está puesto en la esfera material.

En este sentido, pese a la diferencia de acento o énfasis, el marxismo estándar comulga con el liberalismo al minimizar, como este, lo político. El primero amparándose en un economicismo metafísico que convierte la política en mera administración de la comunidad; el segundo, al sostener un individualismo también metafísico, que exalta las libertades individuales en desmedro de la comunidad.

Así las cosas, las relaciones entre libertad (lo formal) y justicia (lo material) que han establecido tanto el liberalismo como el marxismo estándar incurren en la falacia del falso dilema al plantear, el primero, la preeminencia de la libertad sobre la justicia, y el segundo, la de la justicia sobre la libertad. En este sentido, la relación señalada no es de carácter dilemático sino dicotómico pues, como

ya hemos insistido demasiado[,] hay que articular lo diverso y necesario simultáneamente en la complejidad para alcanzar lo suficiente: la fundación de la libertad (condición absoluta de la legitimidad y de la "pretensión política de justicia”) es tan necesaria como la erradicación de la pobreza o la injusticia ecológica, económica y cultural (lo material). (Dussel, 2009, p. 218) 
En este orden de ideas, la política de la liberación pretende que el campo económico cumpla, mediante el ejercicio que le delega la comunidad a través de la acción estratégica y las instituciones políticas, con las máximas exigencias materiales (o de contenido), a saber: la felicidad de todos los miembros de la comunidad política y la reproducción y acrecentamiento de la vida humana en comunidad ${ }^{5}$.

En cuanto al poder y el trabajo, instancias fundamentales de los campos político y económico, es necesario comprender que ninguno de los dos tiene preeminencia sobre el otro puesto que los dos responden a la producción y reproducción de la vida, última instancia que tiene en la cultura su totalidad estructural (en tanto subsume los campos político y económico transversalmente distribuidos en una infinidad de campos como el ecológico, el técnico, el científico, etcétera). En este sentido, la cultura constituye también la última instancia material de la vida.

El Estado es, por su parte, en este juego de lo formal-material, la institución política con mayor grado de complejidad funcional pues allí deben converger la democracia, la responsabilidad de garantizar y reproducir la vida de todos los ciudadanos y la administración o gobierno de la comunidad política. Dicho de otro modo: en el Estado deben armonizarse las funciones de las esferas formal (democracia), material (reproducción de la vida) e institucional (de factibilidad) para hacer viables los principios de la democracia y la posibilidad de una vida digna. En este orden de ideas, entre la revolución del proletariado para tomarse el Estado y la destrucción de este que propugna el anarquismo, debe abrirse espacio su transformación para convertirlo en la institución más importante a la hora de fijar las mediciones que hagan factible la vida en el marco de la dignidad y la justicia.

La política de la liberación, entonces, defiende la tesis de la transformación del Estado frente a las políticas que plantean la revolución, para tomarse su poder (marxismo) o para destruirlo (anarquismo). A propósito, vale anotar que la transformación del Estado procura su refundación ontológica al deconstruir concepciones que lo definen con arreglo al ejercicio de la dominación. En consecuencia, es importante comprender,

5 Para Dussel esta propensión no encuentra eco en otras filosofias politicas -como las de Carl Schmitt, Hannah Arendt, John Rawls o Jürgen Habermas-, en las que la relación de codeterminación entre lo político, lo económico y lo institucional no es abordada, y aún menos en propuestas como las de Friedrich Hayek y Robert Nozick (anarquismo de derecha), en las que lo político se disuelve en función de un mercado sacralizado. 
como lo advirtiera Michel Foucault, que esta institución política no constituye la única institución del cuerpo social.

En consecuencia, una política de la liberación debe superar la estadolatría del marxismo estándar sin caer en el antiestatismo del anarquismo, lo que requiere de otras transformaciones de la izquierda respecto a ciertas determinaciones materiales o de contenido, e institucionales o de factibilidad. Entre las primeras se encuentra la religión ${ }^{6}$, tema que el marxismo estándar y la izquierda eurocéntrica en general no pudieron asimilar como consecuencia del racionalismo positivista que permanece latente en el trasfondo de sus presupuestos teóricos, pero importante como narrativa para el imaginario popular de la comunidad política. Entre las segundas, es importante que la izquierda comprenda que el ejército no constituye per se una institución reac-

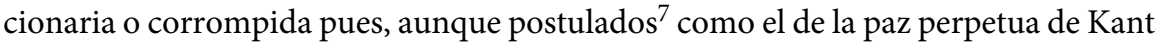
exijan su anulación, es necesario considerar que su desmonte no puede ser inmediato sino progresivo. Además, porque la naturaleza del ejército desde la perspectiva de la política de la liberación es la de una institución que sirve a la comunidad política en el marco de posibles guerras defensivas.

\section{En el nivel de los principios implícitos fundamentales}

El tercer nivel de la Arquitectónica brinda la oportunidad a Dussel de ultimar la exposición de las que en su criterio son las condiciones mínimas, necesarias y suficientes de la propuesta transontológica denominada política de la liberación. Respecto a los equívocos de la izquierda su análisis aborda las siguientes temáticas: a) interpretaciones reductivas del marxismo estándar y del anarquismo bakuninista en torno a la codeterminación entre los principios material, formal y de factibilidad, cuyas tesis ponen respectivamente el acento en el primero y el tercero; b) el carácter

6 Desde la perspectiva dusseliana el tema de la religión reviste un significado especial en un proceso de refundación ontológico-política. La razón: narrativas como la teología de la liberación representan una justificación de la existencia para pueblos como el latinoamericano. Se trata de un significado especial que con razón señala el teólogo Dussel en su crítica a la incapacidad del marxismo estándar para comprender la importancia de la religión a causa de un racionalismo positivista eurocéntrico. Curiosamente, una incapacidad equivalente parece mostrar Dussel mismo respecto a algunos sectores del anarquismo pues desconoce, por ejemplo, la producción teórica y la apuesta política de personalidades como Lev Tolstói y Simone Weil.

7 Importantes como ideal regulativo para el devenir de una sociedad que promueva la afirmación de la vida como instancia ontológico-política fundamental. 
utópico de sus teorías políticas frente a los postulados o ilusiones trascendentales que representan el comunismo y la disolución del Estado; c) el individualismo metafísico del anarquismo y la inversión ontológica del poder político, o fetichización de la potestas del marxismo, referida a obviar las exigencias normativas en la instauración legítima de un Estado democrático. Las consideraciones enunciadas en el análisis son del siguiente tenor.

La Arquitectónica señala la importancia de superar el escepticismo que ha sacudido a la filosofía política desde la caída del socialismo real en 1989 afirmando, contra la desazón que ha infligido el pensamiento posmoderno, la importancia y urgencia de las reglas o principios fundamentales sin los cuales los sistemas sociales serían inviables. Es decir, no hay que soslayar la importancia de lo normativo en la dinámica de los actores sociales, sus acciones estratégicas e instituciones políticas. O dicho de otra manera: "Los principios [...] se sitúan como un a priori ontológico debajo de los constitutivos mismos del poder, en todos los momentos de su despliegue” (Dussel, 2009, p. 348). En este sentido, es comprensible que en la Arquitectónica se aborde la naturaleza implícita de los principios de la acción política, su importancia y la necesidad de explicitarlos de cara a la formación de una conciencia normativa que posibilite la liberación de los pueblos expoliados por el Ego Domino.

En este orden de ideas, es importante señalar los siguientes presupuestos teóricos:

1. Son tres los principios implícitos: el material, el formal-democrático y el de factibilidad estratégica.

2. Su comprensión demanda "diferenciar claramente los principios éticos de los políticos [...] y estos de los postulados políticos" (Dussel, 2009, p. 357) enfatizando a su vez que "los principios éticos son subsumidos en todas las acciones e instituciones políticas, pero bajo las exigencias de obligaciones políticas" (Dussel, 2009, p. 377).

Vale la pena precisar la naturaleza de estos presupuestos teóricos. El principio material es la regla constitutiva de la política pues orienta las acciones e instituciones de la comunidad hacia la producción, la reproducción y el mantenimiento de la vida. Esta condición le implica cuidar "la carnalidad real y concreta de cada sujeto" (Dussel, 2009, p. 395) en cuanto expresión del ámbito trascendental de lo ético en la 
política pues como "principio material de la política es semejante al principio ético (en aquello del respeto absoluto a la vida humana y a su desarrollo)" (Dussel, 2009, p. 392). Ahora, la diferencia entre lo ético y lo político en este principio estriba en que la primera variable (la ética) se pregunta por la validez de las acciones que reproducen la vida con arreglo a formulaciones abstractas mientras la segunda (lo político) define la legitimidad de dichas acciones con arreglo a la legitimidad de los actores y las mediaciones institucionales.

En cuanto al principio material-democrático debe comprenderse que es la regla que constituye y alienta el sistema coercitivo (monopolio de la potestas) de las instituciones. Fundamenta normativamente lo que obliga a los sujetos de la comunidad política y establece razones de simetría entre estos de manera pública y a través del consenso social.

La coerción institucional es legítima siempre y cuando sea producto del reconocimiento que la comunidad política otorgue a la mayoría de sus actores que hayan conquistado la hegemonía tras los procesos de deliberación. Dicha coerción "obliga" a respetar las normas e instituciones dispuestas para producir, reproducir y mantener la vida sin soslayar ni el derecho de las minorías a conquistar la hegemonía legítima ni la posibilidad de renovar las mediaciones institucionales que fetichicen la potestas en menoscabo de la potencia.

Respecto al principio de factibilidad estratégica puede afirmarse que constituye la regla mediante la cual quienes detentan las potestas, como poder delegado por la comunidad política, gobiernan administrando los recursos necesarios para mantener y mejorar la vida de todos. Tal principio además se ocupa de maniobrar entre la necesidad material de producir y reproducir la vida, las imposibilidades empíricas que lo amenazan y las exigencias normativas que demandan su cumplimiento.

Ahora bien, tal como se ha advertido en los apartes que han abordado las determinaciones de la acción estratégica y el nivel político institucional, es importante señalar que no existe relación de preeminencia o yuxtaposición entre los principios material, formal y de factibilidad, puesto que la política de la liberación implica la codeterminación sin última instancia entre estos. La razón: superar las interpretaciones reductivas en la política, que respecto al nivel de los principios de la normatividad política se sintetizan en los economicismos, los formalismos y los decisionismos. 
Los primeros ponen el acento en el principio material y están representados por el neoliberalismo, que promueve el mercado total, y el marxismo estándar, que defiende la planificación total de la economía. Los segundos, representados por el liberalismo, el contractualismo, la ética del discurso y la teoría del derecho habermasiana tienen como común denominador priorizar el principio formal. Los últimos están representados, por su parte, por planteamientos teóricos como los de Maquiavelo, Henry Kissinger, Carl Schmitt o Ernesto Laclau, quienes subrayan el principio de factibilidad como el más importante al fijar respectivamente su atención en la acción estratégica, la política como mero interés, la decisión en el estado de excepción y la lucha por la hegemonía. Ahora, el decisionismo también confronta al anarquismo de izquierda y al de derecha, en cuanto ambos propenden a la destrucción de las mediaciones institucionales, y en consecuencia, a la anulación del principio de factibilidad.

Esta disquisición que la política de la liberación hace en torno a los principios de la normatividad política la obliga a dialogar con planteamientos como el de Hans Jonas, quien en El principio de responsabilidad plantea una fundamentación ontológica (desde el ser) de una ética teleológica que considera a la tecnología como el mayor peligro para la preservación de la vida. Frente a esta consideración la Arquitectónica constituye una política que intenta en cambio una fundamentación transontológica, desde la realidad viviente (no desde el ser), que subsume una ética de la vida humana como finalidad de la acción, contraria a la lógica de la ganancia desmesurada del capitalismo, el verdadero peligro (Dussel, 2009, p. 394).

Además del diálogo en mención, la política de la liberación debe someter a crítica deconstructiva el carácter utópico de los postulados o "ilusiones trascendentales" de las teorías de izquierda, tales como la instauración del comunismo o la disolución del Estado, puesto que los respectivos planteamientos, marxista y anarquista (bakuninista), constituyen apenas formulaciones teóricas consistentes lógicamente pero inviables empíricamente. Dicho de otro modo: constituyen postulados, ilusiones trascendentales o utopías cuya única función política es proveer criterios de orientación para la comunidad política en su lucha por la producción y el acrecentamiento de la instancia fundamental: la vida.

Es importante también comprender que "el principio es exigencia normativa pero no una descripción conceptual con contenido" (Dussel, 2009, p. 437). En consecuencia, la fundamentación transontológica de la política de la liberación no esgrime 
una receta con pretensión universalista como alternativa a la democracia liberal y a las ilusiones trascendentales que han pretendido transformarla desde la izquierda o remozarla desde algunos de los modelos que, por ejemplo, expone David Held en Modelos de democracia. Así, la refundación transontológica propuesta critica con vehemencia a la democracia liberal, mas reconoce que es importante "transformar las formas de gobierno articulando una democracia representativa con una democracia participativa"8 (Dussel, 2009, p. 433). Y comprende también que en algunos momentos históricos excepcionales otras formas de gobierno - monarquía, dictadura, populismo, etc. - se justifican hic et nunc (aquí y ahora) sin que per se representen la mejor opción.

Luego, la defensa de una democracia en la que la legitimidad y la factibilidad determinen la acción de un gobierno que obedezca a la potencia de la comunidad política en el ejercicio de la potestas, implica comprender las relaciones potestas-ley y autoridadliderazgo. En este sentido, es importante comprender que la fuente del poder político es la potencia, y que en consecuencia, esta determina a la potestas u orden institucional. Mas esta última "no está obligada por ninguna ley, porque es la fuente de todas las leyes, y, por ello, por ser fruto del común acuerdo libre y autónomo, deben todos los miembros de la comunidad obedecerla" (Dussel, 2009, p. 400). En cuanto a la relación autoridad-liderazgo ha de saberse que ninguna individualidad solipsista puede ser causa legítima de un orden político basado en el consenso de la comunidad. Lo contrario sería caer en el individualismo metafísico del liberalismo y del anarquismo de izquierda (Bakunin) o de derecha (Nozick).

La fundamentación transontológica en las comunidades políticas de los pueblos poscoloniales implicaría entonces el principio formal discursivo-racional sin fijarlo, ya se ha advertido, como última instancia de la política. Esto en la medida en que tal principio constituye el procedimiento para establecer decisiones entre los actores políticos o ciudadanos en torno a las acciones e instituciones que regulan el orden social. Como principio democrático promueve así la virtud necesaria para establecer un Estado de democracia que fundamente el Estado de derecho. De este modo, la participación

8 Al respecto anota Dussel que la transformación del orden vigente, o mejor, la liberación política exige creatividad política de acuerdo a las condiciones concretas de la comunidad politica. Se requiere ese tipo de creatividad contextual, por ejemplo, para articular "un Estado pluricultural, pluriétnico, plurirreligioso en un mismo territorio [puesto que] en nuestra época no puede pensarse en abstracto una forma de gobierno como la mejor universalmente [...] se trata de un idealismo falto de realismo histórico y político" (Dussel, 2009, p. 432). 
de los actores políticos — desde el barrio hasta la complejidad del Estado- reviste de legitimidad la potestas e impulsa la eficiencia en la administración de lo público por parte de quienes han sido "mandados" a obedecer como representantes de la voluntad general.

El binomio legitimidad-eficiencia pasa de este modo por el principio formal enunciado, mas como se ha insistido, la democracia no se reduce a este pues implica los principios material y de factibilidad en el manejo de los recursos finitos y necesarios para la producción de la vida y la gobernabilidad con las mediaciones institucionales. La codeterminación de los tres principios posibilitaría así la instauración de un Estado democrático en el que la acción de gobierno administra no solo los recursos necesarios para la vida, sino las acciones de quienes gobiernan para compensar las equivocaciones inherentes a la incertidumbre que signa a las decisiones políticas, afirmar los aciertos y establecer decisiones a largo plazo.

Vista así la res-publica, la pretensión de justicia del campo político subsume la pretensión de bondad de la ética. Así se configuran las condiciones necesarias y suficientes para superar el legalismo kantiano y promover el consenso como exigencia normativa entre los actores políticos a partir de su convicción interior respecto a la importancia y necesidad de la normatividad política, las mediaciones institucionales y el compromiso colectivo (intersubjetivo) que representa el poder de la voluntad por la vida.

La refundación de la política vista desde esta perspectiva implica por supuesto una confrontación con el elitismo de derecha (como el que propugnan Schmitt, al reducir la política al esquema amigo-enemigo, y Weber, al limitarla a un mero ejercicio de dominación), pero require sobre todo un aprendizaje de la izquierda respecto a la corrupción ontológico-política en la que han incurrido los "vanguardismos, comités centrales, dictaduras del proletariado, [y] democracias centralizadas" (Dussel, 2009, p. 428) al invertir la relación potentia-potestas en la acción de gobierno soslayando la importancia de los principios y cayendo en la fetichización de la potestas.

\section{Consideración final}

Este texto pretende aportar un grano de arena a la gran obra Arquitectónica del maestro de la liberación latinoamericana pues, pese a los elementos críticos que contiene en relación con su obra, hace propia la exhortación que en ella se expone acerca de 
la esencialidad del disenso minoritario en relación con la democracia ${ }^{9}$. En este sentido, es justo reconocer que la crítica de la filosofía política dusseliana es más que un esfuerzo encomiable por complementar la crítica de la economía política de Marx: constituye además un síntoma de excelente salud para el proyecto de transontologización desde la periferia poscolonial.

De otro lado, es saludable también señalar que la lucha por la producción y reproducción de la vida humana en comunidad y contra la fetichización de la potestas exige comprender que la resistencia a favor de la potencia ha sido agenciada desde distintas orillas de la izquierda, y que dentro de esta el anarquismo - que también es poliédrico y no solo bakuninista— representa más que una bolsa de postulados.

Así las cosas, Dussel exhorta a la izquierda, desde la perspectiva del liberacionismo, para que asimile el proceso del socialismo real y el marxismo de estirpe althusseriana y brinde así la apariencia de un "examen de conciencia", una especie de introspección que la lleve a asimilar los errores y horrores acontecidos en la Unión Soviética. Pero ese proceso sería más significativo si, como lo expone Lehning (2008), no se obviara la crítica que desde la orilla anarquista se hiciera cuando la revolución leninista era apenas incipiente o estaba en plena ebullición y aún no se vislumbraba el final del trágico experimento soviético.

Desde esta perspectiva el anarquismo de izquierda podría ser subsumido por la política de la liberación siempre y cuando esta última esté dispuesta a reconocer los aportes teóricos y revolucionarios de aquella tradición libertaria en un análisis que destaque las semejanzas o simetrías conceptuales entre las categorías históricas del anarquismo y las propuestas en la Arquitectónica.

\section{Referencias}

Cappelletti, J. (1978). Génesis y desarrollo de la filosofía social de Kropotkin. Revista de Filosofía de la Universidad de Costa Rica, 44, 143-152.

Dussel, E. (2007). Política de la liberación. Historia mundial y crítica. Madrid: Trotta.

9 "El disenso minoritario es esencial en el proceso democrático [...] es decir, cuando el consenso anula o elimina el disenso, se niega el Principio democrático y se cae en el autoritarismo, despotismo o dictadura de las mayorias, que impedirá el desarrollo de una democracia" (Dussel, 2009, p. 18). 
Dussel, E. (2009). Política de la liberación. Volumen II: arquitectónica. Madrid: Trotta.

Lehning, A. (2008). Marxismo y anarquismo en la Revolución rusa. Buenos Aires: Utopía Libertaria.

Ochoa, J. (2015). Deconstrucción de la izquierda e interpretación reductiva del anarquismo en la arquitectónica dusseliana. En I. Herrera, J. Ochoa y A. Silva, Filosofía latinoamericana actual: historia de las ideas, política de la liberación, sentipensar ontológico (pp. 32-57). Recuperado de https://repository.usta.edu.co/ handle/11634/442

Pachón, D. (2012). Historiografía, eurocentrismo y universalidad en Enrique Dussel. Ideas $y$ Valores, 61(148), 37-58. Recuperado de https://revistas.unal.edu.co/index. $\mathrm{php} /$ idval/article/view/36793/38796

Weber, M. (2012). Economía y sociedad. México: FCE. 